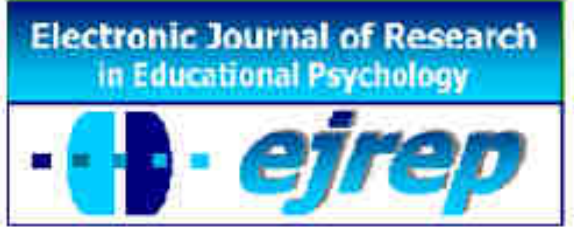

\title{
Epistemological and reading beliefs profiles and their role in multiple text comprehen- sion
}

\section{Mar Mateos ${ }^{1}$, Isabel Solé ${ }^{2}$, Elena Martín ${ }^{3}$, Nuria Cas- tells $^{2}$, Isabel Cuevas ${ }^{3}$ y Jara González-Lamas ${ }^{1}$}

${ }^{1}$ Departamento de Psicología Básica, Universidad Autónoma de Madrid, Madrid

${ }^{2}$ Departamento de Psicología Evolutiva y de la Educación, Universidad de Barcelona, Barcelona

${ }^{3}$ Departamento de Psicología Evolutiva y de la Educación, Universidad Autónoma de Madrid, Madrid

Spain

Correspondence: Mar Mateos. Departamento de Psicología Básica. Facultad de Psicología.Universidad Autónoma de Madrid. Campus de Cantoblanco. 28049 Madrid. Spain. E-mail: mar.mateos@uam.es

(C) Education \& Psychology I+D+i and Ilustre Colegio Oficial de la Psicología de Andalucía Oriental (Spain) 


\section{Abstract}

Introduction. The aim of this study was to analyse the role of epistemological beliefs and reading beliefs in the comprehension of multiple texts which presented conflicting positions about a controversial topic (nuclear energy). More specifically, we investigated the influence of the multidimensional configuration of epistemological and reading beliefs on multiple text comprehension.

Method. The participants were 476 university students from two different Spanish universities, and diverse studies (Humanities, Health Sciences, Architecture and Engineering). In a whole-class session, the Epistemological Beliefs Questionnaire (EQEBI) and the Reader Belief Questionnaire were first administered. In the second part of the session participants completed the prior knowledge questionnaire and performed the multiple text comprehension task.

Results. Using cluster analysis we identified two distinct beliefs profiles: sophisticated, in which the more sophisticated epistemological beliefs were associated to more transactional and less transmissive reading beliefs; and naïve, in which the more naïve epistemological beliefs were associated to less transactional and more transmissive reading beliefs. Relationships were found between profiles and gender and domain of knowledge. In addition, after controlling prior knowledge, students with a more sophisticated epistemological and reading beliefs' profile obtained a higher level of multiple text comprehension than those with a more naïve profile.

Conclusion. Consistent with prior research, we may interpret that students who understand knowledge in a more sophisticated way tend to view reading less as a transmissive process and more transforming of knowledge; therefore, they get involved in a deeper comprehension of the different sources and this favours their ability to process information and make inferences - at an intra and inter textual level.

Keywords: Belief profiles, epistemological beliefs, multiple text comprehension, reading beliefs, university students. 


\section{Perfiles de creencias epistemológicas sobre la lectura y su papel en la comprensión de textos múltiples}

\section{Resumen}

Introducción. El ojetivo de este estudio fue analizar el papel de las creencias epistemológicas y de lectura en la comprensión de multiples textos que presentan posiciones contradictorias sobre un tema controvertido (la energía nuclear). En concreto, se investigó la influencia de la configuración multidimensional de creencias epistemológicas y de lectura en la comprensión de múltiples textos.

Método. En el estudio participaron 476 estudiantes universitarios de dos universidades españolas y de distintas titulaciones (Humanidades, Ciencias de la Salud, Arquitectura e Ingeniería). Durante una clase se aplicó el Epistemological Beliefs Questionnaire (EQEBI) y el Reader Belief Questionnaire. En la siguiente, los participantes contestaron el cuestionario de conocimiento previo y realizaron la tarea de comprensión a partir de múltiples textos.

Resultados. Se identificaron dos perfiles de creencias a través de un análisis de cluster: sofisticado, en el que las creencias epistemológicas sofisticadas están asociadas con creencias sobre la lectura más transaccionales y con las menos transmisivas; e ingénuo, en el que las creencias epistemológicas más ingenuas están asociadas con creencias sobre la lectura menos trasaccionales y con las más transmisivas. Se encontraron relaciones entre los perfiles y el género y el dominio de conocimiento. Los resultados muestran también que, una vez controlado el conocimiento previo, los estudiantes con creencias epistemológicas y de lectura más sofisticadas obtienen mejores resultados en la tarea de comprensión a partir de múltiples textos que aquellos que responden a un perfil ingenuo.

Conclusion. Según los resultados, que coinciden con los de otros estudios, interpretaríamos que los estudiantes que conciben el conocimiento de una manera más sofisticada tienden a considerar la lectura menos como un proceso transmisivo y más como una transformación del conocimiento; por ello realizan una comprensión más profunda de las diferentes fuentes y esto favorece su capacidad de procesar información y hacer inferencias -en un nivel tanto inter como intra textual.

Palabras Clave: perfiles de creencias, creencias epistemológicas, comprensión a partir de multiples textos, creencias sobre la lectura, estudiantes universitarios. 


\section{Introduction}

Understanding multiple texts is a necessity in the society of knowledge (Goldman, 1997) and, specifically, at university (Mateos \& Solé, 2009; Tynjälä, 2001). In spite of this, university students are, to a large extent, unfamiliar with these kinds of tasks and find them difficult to tackle. Spanish university students are no exception (Mateos \& Solé, 2009; Mateos, Villalón, de Dios \& Martín, 2007; Solé et al., 2005). The comprehension of multiple texts is a more demanding task than grasping the meaning of a single text. Whereas in the latter case, comprehension is based on establishing coherent relationships between both local and global ideas, information gleaned from multiple texts cannot always be integrated by looking for coherence, particularly when the different sources offer contradictory information. For this reason, attending simultaneously to various sources requires putting into action specific mechanisms of integration (Britt, Perfetti, Sandak, \& Rouet, 1999).

The comprehension of texts is dependent on multiple factors (personal, the task itself and the context) (Alexander \& Jetton, 2000; Goldman, 1997); traditionally, there has been a lot of research into some of these (for example, the role of prior knowledge or of the structure of the text), whereas others have only been researched more recently. Amongst the latter, there is the role of beliefs on knowledge and beliefs about reading itself. These beliefs may act as filters that determine the way students represent and handle reading (Simpson \& Nist, 2000). The role that both types of belief play on understanding has been researched separately (Schommer, 1990; Schraw \& Bruning, 1996). In the paper, the point of departure is the assumption that both types of belief are not independent of each other but, rather, that they are related (Mateos et al., 2011). The aim of this paper is to analyse the role of epistemological beliefs and reading beliefs in the comprehension of multiple texts which present conflicting opinions about a controversial subject.

\section{Epistemological Beliefs and Comprehension of Multiple Texts}

Dealing with multiple texts to integrate different perspectives of an issue may be influenced by the beliefs the individual holds about the nature of the knowledge. The study of epistemological beliefs has been approached from different standpoints (Hofer \& Pintrich, 1997, 2002; Schommer, 1990). Schommer's model (1990; Schommer- 
Aikins, 2002) considers the nature of knowledge too complex to be "captured" on a single dimension, which leads her to postulate a set of epistemological beliefs organised into a system, though relatively independent of each other. The model proposes four dimensions and assumes that people can hold sophisticated beliefs on some of these dimensions and naïve beliefs on others:

- The certainty of knowledge; the belief according to which knowledge is certain implies the existence of absolute knowledge that can be known. The opposite belief, in this case, is that knowledge is uncertain, ambiguous.

- The simplicity of knowledge; the belief according to which knowledge is simple implies holding that it consists in aggregates of discrete facts. The opposite belief leads to considering knowledge as complex and interconnected.

- The immediacy or quickness of learning: the belief according to which people learn-or fail to learn-immediately, as opposed to the belief that learning is a process.

- The ability to learn, which can be conceived of as an innate ability or, at the opposite extreme, as an acquired ability.

Certainity and Simplicity refer to the nature of knowledge, while Immediacy and Ability are beliefs about the knowledge acquisition process. Also Hofer and Pintrich (2002) consider epistemological beliefs referring to beliefs about the nature of knowledge - not about learning. Several studies have shown the influence of gender, educational level or experience and the domain of knowledge in epistemological beliefs. Schommer (1993) found that women tend to display more sophisticated beliefs; this result was supported in other research (Mason, Boldrin, \& Zurlo, 2006), but Hakan and Munire (2012) find male students believe more than female that learning depends on effort. Other studies (Nayebi \& Tahiri, 2014) however did not find gender-related differences in the degree of sophistication in beliefs. Studies that have examined the role of educational level or experience in beliefs have yielded different results depending on the level at which they were carried out. Schommer (1998) found that university students have more sophisticated beliefs than secondary school students. In another study, Jehng, Johnson and Alexander (1993) identified no differences between university students in different years, but found differences between graduate and undergraduate students. Likewise, other studies performed on large samples of first- and last-year univer- 
sity students (Hakan \& Munire, 2012) failed to report effects due to educational experience among university students. Nevertheless, differences were found in both studies on comparing students in different domains, albeit not in every epistemological dimension. In particular, Hakan and Munire (2012) reported that students of Applied Sciences believe that knowledge is certain, to a greater extent than students of Social Sciences. These students also consider more than those of Applied Sciences that learning depends on effort. The authors considered that their results corroborated those of Jehng et al. (1993), who found that students in hard domains -engineering- are more naïve than humanities students -soft domain.

These results leave open the controversy regarding whether epistemological beliefs are of a general or domain-oriented nature. The review by Muis, Bendixen and Haerle (2006) dismisses addressing this question in exclusive terms. On the one hand, because individuals hold general beliefs about knowledge, but they may make distinctions among the dimensions in relation to particular domains of knowledge. On the other hand, because other research into whether students of different domains have different epistemologies has, indeed, found differences; but on analysing the results of said studies many similarities are also found. Muis and colleagues attribute this fact to possible differences among domains regarding certain epistemological characteristics while others are shared (soft/hard; pure/applied; well/ill structured). Therefore, although it could be expected that individual beliefs become more consistent with the epistemic pattern of their domain of study, continuity in individuals belonging to different domains with regard to beliefs on the nature of knowledge is also to be expected, and they conclude that both coexist in the personal epistemology.

Researches that have studied the effect of beliefs in universtiy students who read a text presenting conflicting perspectives on a same topic have found that Certain Knwoledge belief is related to the production of absolute conclusions (Kardash \& Scholes, 1996; Schommer, 1990). In this line, conceiving knowledge as relative, uncertain, may be related to the capacity to integrate controversial or different positions about a topic, presented in two or more texts.

In a recent review, Bråten, Britt, Strøms $\varnothing$, and Rouet (2011) summarised the most relevant results found in their own studies -and other research papers- analysing 
the impact of more or less sophisticated beliefs about a specific topic (climate change) held by education undergraduates on multiple text comprehension, adopting the Hofer and Pintrich (1997) model. Thus, the belief that knowledge is complex favoured comprehension, intertextual integration and elaboration across the texts presenting different perspectives. Perceiving knowledge as tentative and changing leads to a greater comprehension and integration, benefits tasks which involve constructing arguments (above those that require summarising and global understanding) and allows for a better coverage of complex and uncertain knowledge.

Summarising, beliefs related to simplicity / complexity and accuracy / ambiguity of knowledge appear to gain an unquestionable support in the various papers reviewed, including those carried out from different perspectives (see also Buehl, 2008; Pieschl, Stahl \& Bromme, 2013).

\section{Reading Beliefs and Comprehension}

Reading beliefs have been investigated adopting the implicit theories or models approach. In the pioneer research on this topic, Schraw and Bruning (1996; Schraw, 2000) consider two implicit independent models of reading, each of them leading to different engagement patterns among readers. The transmission model involves the belief that meaning must be transmitted from the author and/or the text into the reader's memory. This model predisposes readers to be passive takers of meaning. The transaction model involves the belief that meaning must be actively constructed by readers integrating their own thinking into the process. Transactional beliefs lead to more critical and personal engagement during reading. Using the Reader Belief Questionnaire, Schraw and Brunning (1996) assessed the beliefs of university students. They found better reading comprehension results for those students holding transactional reading beliefs: after reading a story, they write commentaries including critical assessements and personal reactions. The results of Schraw's (2000) work showed that transactional beliefs - but not those of transmission - were associated to a deeper and more integrated comprehension of narrative texts. Likewise, transactional beliefs were also positively related to remembering whereas transmission beliefs were negatively associated to this respect. 
Using the Reading Questionnaire Beliefs (Schraw \& Brunning, 1996), Dai and Wang (2007) partially replicated the findings of previous Schraw and Brunning studies and confirmed the positive effects of transactional beliefs on reading narrative and expository texts. These authors also reported a consistently negative effect of transmission beliefs on the comprehension of both types of text. Moreover, they observed that students with high transmission beliefs gave up more easily when facing difficulties in reading. This led them to conclude that the transactional model - which Dai and Wang (2007) see as reflecting more sophisticated beliefs - emerges as a decisive factor in attempting to explain the influence of reading beliefs on comprehension.

In the research described above, the role of beliefs on reading in the comprehension of a single narrative or expository text was analysed. The paper aims to extend these results to reading situations across multiple expository texts.

Epistemological beliefs, reading beliefs and the integration of information from multiple sources

Although the constructs "epistemological beliefs" and "reading beliefs" have been proposed and researched separately by different traditions, they do bear some similarities. From a conceptual point of view, both refer to ways of perceiving knowledge or meaning -and its acquisition - and both are associated to the degree of personal involvement in the comprehension of the text and its level of elaboration or processing. Both constructs lead to the prediction that students with more sophisticated beliefs will achieve greater levels of comprehension than students with more naïve beliefs. However, in spite of the fact that both share the same conceptual space, there is very little empirical evidence that links both types of belief with comprehension. The only research we are aware of in which these relationships have been investigated, is a prior study by our own team (Mateos et al., 2011). In this research, psychology undergraduates were asked to read two texts presenting conflicting perspectives on the same topic and to write a reasoned conclusion. The results showed the existence of a relationship between the epistemological beliefs held by students and their reading and writing beliefs. Students with a complex perception of knowledge tend to be more in agreement with transaction reading and writing beliefs and less in agreement with transmission reading and writing beliefs. 
Lastly, research focusing on the relationship between the comprehension of multiple texts and beliefs -epistemological or reading beliefs- usually relies on linear data analysis. These studies look for correlations between the dimensions of reading or epistemological beliefs and reading comprehension. Some of them use regression analysis to identify the specific dimensions of beliefs related to comprehension. From another standpoint, Buehl and Alexander (2005) assume that beliefs belong to a complex system, that is to say, they are not isolated. These authors used clusters to identify specific configurations of epistemological beliefs related to the motivation and performance of the participants in a text-based learning task, producing encouraging results for further research. Also, Ferguson and Bråten (2013) profiled secondary school students using cluster analysis on the basis of more than one dimension of epistemic beliefs, and examined differences in multiple-text comprehension among the clusters. A significant step in understanding the structure of the belief system of individuals and its impact on comprehension and learning will be to look into the existence of a possible multidimensional configuration on epistemological and reading beliefs, as well as the influence of different configurations of beliefs on the comprehension of text/s. This research aim which, so far as we know, has not been addressed by prior research, might be attained by grouping or clustering individuals on the basis of their epistemological and reading beliefs and examining the emergent groups with respect to multiple controversial text comprehension.

\section{Aims and Hypothesis}

The aim of this study was to analyse the role that epistemological beliefs and reading beliefs play on the ability to understand information across multiple texts that maintain conflicting positions. More specifically, the aim is to understand the influence of the multidimensional configuration of certainty and simplicity epistemological beliefs and reading beliefs on multiple text comprehension. Likewise, we aim to investigate the possible influence of gender, the domain of knowledge and the educational level in this multidimensional configuration. In order to achieve these goals, we sought to address three key questions:

1) What are the emergent profiles of students' epistemological and reading beliefs? 
2) Do the profiles identified present differences regarding participants' gender, domain and educational level?

3) Does the level of comprehension reached across controversial multiple texts change with respect to the profiles of students' epistemological and reading beliefs?

The following hypotheses were posed in relation to these aims:

1) We expected the students to display different profiles - more sophisticated or more naïve - both in their epistemological and their reading beliefs so that the more sophisticated certainty and simplicity epistemological beliefs are associated to more transactional and less transmissive reading beliefs and the more naïve certainty and simplicity epistemological beliefs are associated to more transmissive and less transactional reading beliefs. Previous research had shown that gender, educational level and knowledge domain are related to epistemological beliefs. However, only one study has linked these variables with reading beliefs (Lordán \& Solé, in preparation). Within this context, and in view of the novelty of identifying profiles, we aim to explore whether the mentioned variables -or their interaction- can be linked in any way to the profiles we expect to find.

2) Likewise, we expected that the students displaying a more sophisticated profile of beliefs would attain a higher level of comprehension than those displaying a more naïve profile when reading several texts presenting conflicting positions about a subject.

\section{Method}

\section{Participants}

The participants were 476 students from two state universities located in two large Spanish cities (Madrid and Barcelona) (see Table 1). With respect to the gender, $29.36 \%$ of the students were males and $70.64 \%$ females. The courses selected formed part of three areas of knowledge: Humanities (Languages and History) (20.17\%), Health Sciences (Psychology) (53.36\%) and Architecture and Engineering (26.47\%). With respect to the variable of the year of study, students from the first year $(59.25 \%)$ and the final years $(40.75 \%)$ participated ${ }^{\mathrm{i}}$. 
Table 1. Distribution of Participants by Area of Knowledge, Year of Study and Gender

\begin{tabular}{|c|c|c|c|c|}
\hline Course and Year of Study & $\mathrm{N}$ & Male & Female & $\begin{array}{c}\text { Not } \\
\text { specified } \\
\text { gender }\end{array}$ \\
\hline \multicolumn{5}{|l|}{ Psychology } \\
\hline 1 st year & 175 & 30 & 142 & 3 \\
\hline Final years & 79 & 13 & 65 & 1 \\
\hline \multicolumn{5}{|l|}{ Humanities (English \& History) } \\
\hline 1 st year & 44 & 12 & 27 & 5 \\
\hline Final years & 52 & 13 & 37 & 2 \\
\hline \multicolumn{5}{|l|}{ Architecture and Engineering } \\
\hline 1st year & 63 & 39 & 21 & 3 \\
\hline Final years & 63 & 29 & 33 & 1 \\
\hline Total & 476 & 136 & 325 & 15 \\
\hline
\end{tabular}

\section{Instruments}

\section{Measurement of epistemological beliefs}

In order to assess epistemological beliefs the EQEBI questionnaire was used (Ordoñez, Ponsoda, Abad, \& Romero, 2009). This instrument integrates and expands on the Epistemological Questionnaire (EQ) (Schommer, 1990) and the Epistemic Beliefs Inventory (EBI) (Schraw, Bendixen \& Dunkle, 2002). The authors of this instrument carried out two validation studies. The samples used in these studies consisted of firstand last-year university students in Psychology, Electronics, Engineering and Languages at Spanish-speaking Universities, and therefore comparable to the sample used herein.

In the initial study, the authors of the EQEBI instrument translated the two tests (EQ and EBI) to Spanish and applied them to a Spanish speaking sample. The results of the monotone homogeneity model and confirmatory factor analysis led the authors to propose a new test and the dimensionality and psychometric properties of the test's scores were determined. The new test has 27 items (on a scale of 1 to 5 , the higher scores indicating a greater degree of naivety) and retains four of the five original dimensions: Simple Knowledge (SK, 4 items), Certain Knowledge (CK, 4 items), Quick Learning (QL, 11 items) and Innate Ability (IA, 8 items).

The EQEBI reliability is higher than that of the original EQ and EBI: Cronbach's alpha for CK was 0.70 , for SK 0.67 , for QL 0.88 and for IA 0.81 . In a sec- 
ond study, the EQEBI was applied to another sample to verify the psychometric properties of the obtained scores. The expected four unidimensional scales are confirmed. The scales are calibrated with the graded response model. In our study only the scores for the scales Simple knowledge and Certain knowledge were used.

\section{Measurement of reading beliefs}

The Reader Belief Questionnaire developed by Schraw and Bruning (1996) was used to assess the students' reading beliefs. The questionnaire includes 14 items (on a scale of 1 to 5) distributed into two subscales of seven items each: transmission belief and transction belief. Cronbach's alpha for transmission belief was 0.502 and for transaction belief was 0.438 .

\section{1) Texts}

Three texts were drawn up on the topic of nuclear energy; one was expository and two were argumentative essays, presenting different positions, one for and one against. The topic of nuclear energy was selected because it is highly controversial and there are several different points of view; it is scientific in nature but at the same time has significant social implications with which students from the different areas of study might be familiar and interested in. The three texts were the result of the adaptation of texts taken from several web pages of official and/or well-known, authoritative and trustworthy sources. In all three texts, information was provided about the sources used and it was indicated that the texts had been adapted. The expository text (760 words, 8 paragraphs) included information necessary to be able to understand the arguments of the other two texts, which was why students read this text first. The text in favour (770 words, 12 paragraphs) and the text against (1,018 words, 10 paragraphs) contained the same number of arguments, eight in each case, related to the same topics.

\section{2) Measurement of prior knowledge}

A test was drawn up with 20 true-false items to assess prior knowledge on nuclear energy. In order to draw up the statements, we used the basic knowledge which should be acquired by the end of Compulsory Secondary Education on these subjects, which, in Spain, is 16 years of age. Cronbach's alpha was .651.

\section{3) Measurement of comprehension across multiple texts}


A test of 22 items was created to assess the comprehension attained from reading the three texts. The students were asked to decide in each case "whether the idea expressed can be deduced (or not) from the information included in the texts you have read". 14 items presented statements that could be answered based on the information in one of the three texts (intra-textual comprehension) and 8 presented statements that required integrating information from at least two of the texts (inter-textual comprehension). In turn, 13 statements were paraphrases of ideas contained in the texts (superficial comprehension) and 9 were inferences extracted from the information given in the texts (deep level comprehension). Finally, 8 were true affirmations and 14 were false. The correct responses, therefore, are produced when it is identified that the true statements can be deduced from the texts, and that the false statements cannot be deduced from the texts.

The measure of comprehension was the total number of correct responses. Separate measures of comprehension in the different dimensions handled were not taken into account due to the fact that the number of items in each was small. The reliability (Cronbach's alpha) of the global measure of comprehension was .510. As in Bråten, Strøms $\varnothing$ and Samuelstuen (2008), presumably, the somewhat low reliability estimates of the verification tasks in the present study were related to the relatively short length of the scales. The high length necessary to obtain a high reliability coefficient was not feasible given the time available for data collection.

\section{Procedure}

The data from each group of students were collected by the researchers in their own classrooms during a session which lasted approximately two hours. During the first part of the session, the two belief questionnaires were completed. The order of presentation was counter-balanced so that half the students in each group responded first to the epistemological beliefs and then to the reading beliefs and the other half responded in reverse order. After a break, in the second part of the session the prior knowledge questionnaire was set and, once it had been collected, the comprehension task.

They all read the descriptive text first but the order of presentation of the other two texts was counter-balanced within each group, so that half the group read first the 
text "for" and then the text "against" and the rest did the reverse. The reading time was not limited so that when the student considered he was ready, the texts were collected in and he was then given the comprehension test. Students included in this study participated voluntarily and provided informed consent for the use of the data collected.

\section{Data analysis}

To examine the extent of the relationship among all belief variables, an initial correlation analysis was carried out. Using the above correlations to determine the multidimensional profiles that would emerge on the basis of students' epistemological beliefs and reading beliefs, we conducted a K-means cluster analysis. We used various methods to determine the appropriate cluster solution. First, potential cluster solutions were examined to ascertain whether the clusters differed in regard to various dimensions of the epistemological and reading beliefs. The results for the cluster analysis were confirmed using the cross-validation method (Everitt, Landau \& Leese, 2001). We randomly split the sample in two equal groups of 238 cases each. We analysed the two data samples separately and compared the cluster solutions to determine whether the emergent clusters were consistent across the samples. This procedure allowed us to identify a two cluster solution (for the two samples as well as for the full data set) as the most appropriate. Finally, once cluster membership was identified, the cluster variable was used to predict group membership. The Cohen's kappa coefficient provides a measure of percentage of correct classifications over and above chance. The kappa index was .98 , which supports the validity and consistency of the classification used for the analyses. To test the statistical differences between the clusters with respect to students' epistemological and reading beliefs we conducted four analyses of variance (ANOVAs) with cluster membership as the independent variable and the different belief scales as the dependent variables. To characterise the distribution of the two belief profiles according to gender, year of studies, and area of knowledge in the selected sample, a chi-squared test was used. Finally, in order to analyse the cluster differences with respect to multiple text comprehension, we conducted an analysis of covariance (ANCOVA) of a single factor with cluster membership as the independent variable, multiple text comprehension as the dependent variable and prior knowledge as the covariable, given the significant correlation between prior knowledge and comprehension. 


\section{Results}

Correlations between epistemological beliefs and reading beliefs, prior knowledge and comprehension of texts

In line with prior research (Mateos et al., 2011) and despite not being the objective of this study, positive and significant correlations were found among the two dimensions of epistemological beliefs (simple knowledge and certain knowledge) (see Table 2). Simple knowledge and certain knowledge also correlated significantly and negatively with transaction reading beliefs, while certain knowledge correlated positively with transmission reading beliefs.

Furthermore, simple knowledge is negatively and significantly correlated with prior knowledge and comprehension, while certain knowledge is negatively associated with comprehension. At the same time, transmission reading beliefs are negatively and significantly correlated with comprehension, while transaction reading beliefs are positively correlated with this variable.

Table 2. Mean, Standard Deviation and Pearson Bilateral Correlations among Epistemological Beliefs, Reading Belief, Prior Knowledge and Comprehension

\begin{tabular}{|c|c|c|c|c|c|c|c|}
\hline Measure & $M$ & $S D$ & 2 & 3 & 4 & 5 & 6 \\
\hline 1. Simple Knowledge & 1.89 & .45 & $.35^{* *}$ & .05 & $-.18 * *$ & $-.10^{*}$ & $-.11^{*}$ \\
\hline 2. Certain Knowledge & 2.21 & .83 & - & $.18^{* *}$ & $-.39 * *$ & -.06 & $-.15^{* *}$ \\
\hline 3. Transmission Reading & 2.73 & .46 & - & - & -.08 & -.08 & $-.10^{*}$ \\
\hline 4. Transactional Reading & 3.89 & .51 & - & - & - & -.08 & $.09 *$ \\
\hline 5. Prior Knowledge & 12.15 & 3.35 & - & - & - & - & $.18 * *$ \\
\hline 6. Comprehension & 15.67 & 2.67 & - & - & - & - & - \\
\hline
\end{tabular}




\section{Epistemological and Reading Belief Profile Groups}

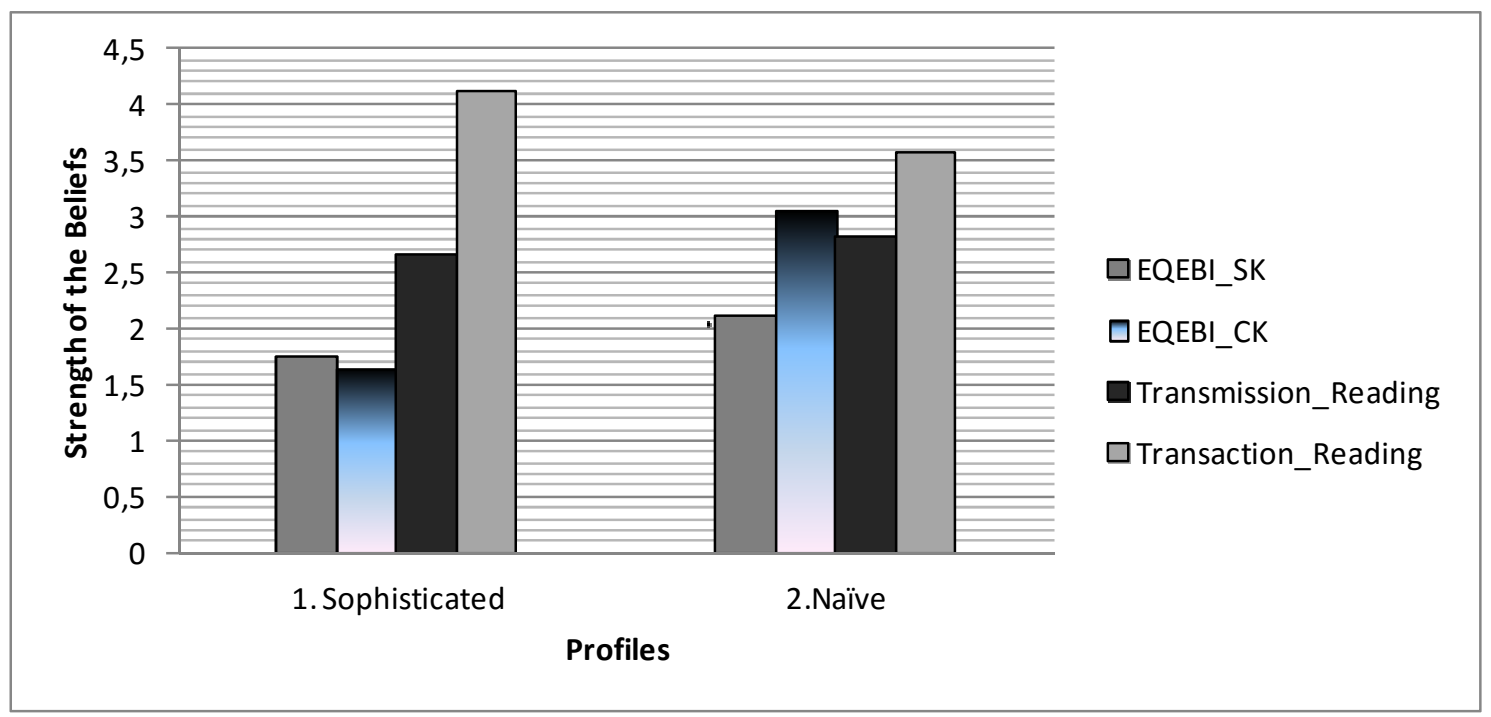

Figure 1. Epistemological and reading beliefs in two cluster profiles

${ }^{1}$ Final-year students taking part in this study were still in the Spanish university model current before the reform according to the European Space for Higher Education. Prior to this reform, undergraduate studies were of three-year duration (Diplomatura) or 5-year duration (Licenciatura).

As can been seen in Figure 1, the cluster analyses carried out with 476 participants in the study, show that epistemological and reading beliefs can be grouped around two profiles, one more sophisticated $(n=282)$, and the other more naïve $(n=194)$. In absolute terms, neither of the two groups is characterised by clear naïve beliefs. In the naïve profile, the values of the simple knowledge beliefs are around the middle mark of the scale, and the values of the certain knowledge beliefs are over, while in the sophisticated profile both scales are below. The transmission reading belief is slightly over the middle mark of the scale in both profiles. In addition, the transaction reading belief is clearly over the middle mark of the scale in the sophisticated profile.

The ANOVAs showed statistically significant univariate effects for simple knowledge belief, $F(1,476)=10.45, p<.001$, partial $\eta^{2}=.17$, certain knowledge, $F(1,476)=325.03, p<.001$, partial $\eta^{2}=.91$, transmission reading beliefs, $F(1,476)=$ 7.47, $p=.018$, partial $\eta^{2}=.06$, and transaction reading belief, $F(1,476)=17.33, p<$ .001 , partial $\eta^{2}=.31$ (see Table 3 for statistically descriptive details). Therefore, it can be assumed that all the variables included in the analyses are useful from the point of view of their contribution to the classification of the cases. 


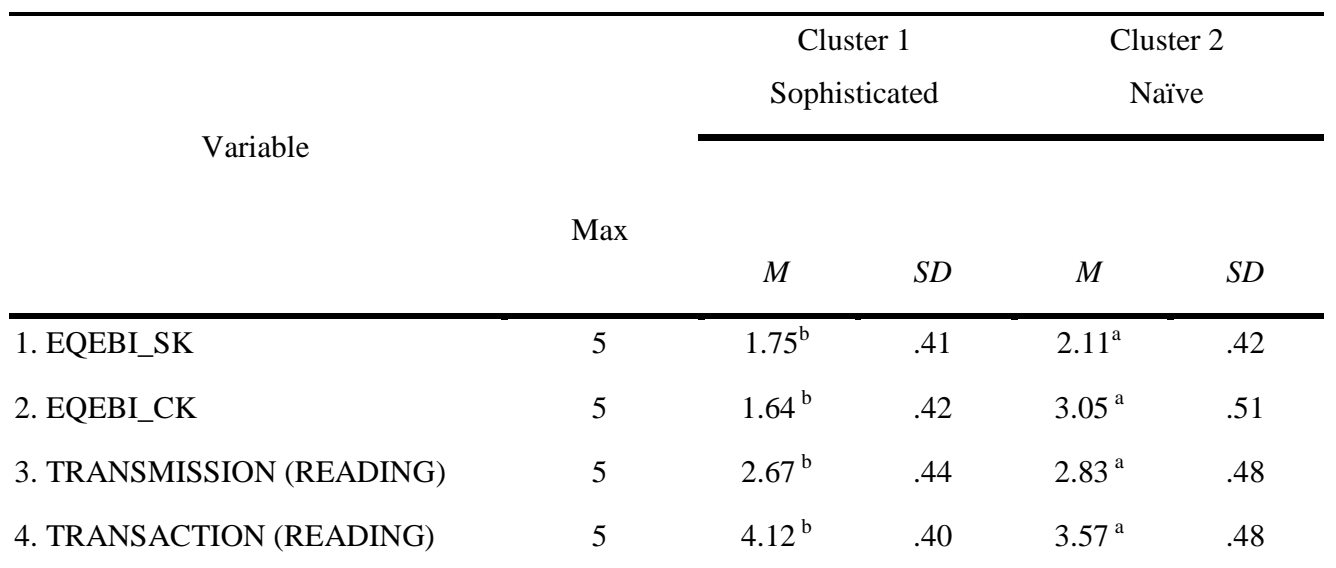

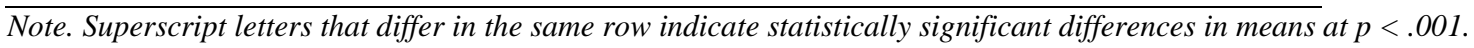

\section{Cluster differences with respect to sample characteristics}

The results showed significant differences in relation to area of knowledge and gender. Specifically, the comparison for the two student profiles (sophisticated and naïve) yielded a significant chi-squared value with respect to the area of knowledge $\left(\chi^{2}(2\right.$, $N=476)=10.08, p=.006 ;$ Cramer's $V=.14)$. In the domain of psychology the percentage of students identified with a sophisticated profile (64.6\%) was higher than expected, while in the domain of engineering and architecture the percentage of students with a naïve profile was higher than expected (52.4\%). Other significant differences involving gender also emerged $\left(\chi^{2}(1, N=470)=6.67, p=.013\right.$; Cramer's $\left.V=.19\right)$. In the women's group, the percentage within the sophisticated profile was higher than expected $(63.6 \%)$, while in the men's group the percentage with a naïve profile $(49.3 \%)$, was also higher than expected. There was a non-significant chi-squared value with respect to years of university experience $\left(\chi^{2}(1, N=476)=.17, p=.18\right)$.

Given that in our sample men and women were distributed unevenly among the various areas of knowledge, we decided to perform a further chi-squared test with the profiles, gender, and the area of knowledge as a layer variable. The results highlighted that the relationship between profiles and gender is significant for the area of knowledge 
encompassing engineering and architecture $\left(\chi^{2}(1, N=122)=5.52, p=.019\right.$; Cramer's $V=.21)$. It is in this domain that a higher percentage than expected of women in the sophisticated profile was identified most clearly (61.1\%), compared to men (39.7\%). By contrast, in the other two areas the distribution of the sophisticated profile between men and women is equivalent (in psychology, $64.3 \%$ of women and $65.9 \%$ of men; in humanities, $63.2 \%$ of women and $53.8 \%$ of men).

These results could be related to male students of engineering and architecture holding more naïve belief profiles than male students of psychology and humanities. A Chi-squared test with profiles and area of knowledge, introducing gender as a layer, showed a significant relationship between profiles and area of knowledge in the case of men $\left(\chi^{2}(2, N=138)=7.46, p=.024\right.$; Cramer's $\left.V=.23\right)$. In line with the above, more men were identified with a sophisticated profile within the domain of psychology than would be expected (65.9\%), against the percentage of sophisticated students identified in engineering and architecture (39.7\%). Contrariwise, no significant differences are identified between the profiles shown by women in each domain of knowledge.

\section{Cluster differences with respect to multiple text comprehension}

In accordance with the ANCOVA results, the R Squared of the model was .065, the effect of the cluster was significant, $F(1,476)=15.86$, Mse $=106.70, p<.001$, partial $\eta^{2}=.032$, and prior knowledge was a significant covariable, $F(1,476)=16.43$, Mse = $110.57, p<.001$, partial $\eta^{2}=.034$. As can be seen in Table 4 , the participants of the more sophisticated profile obtained higher scores on multiple text comprehension than those with the more naïve profile.

Table 4. Descriptive Statistics of Prior Knowledge and Comprehension for the Two Belief Profile Groups

\begin{tabular}{lcccc}
\hline Profiles and variables & $M$ & $S D$ & Min. & Max. \\
\hline Naïve & & & & 19 \\
Prior Knowledge & 12.09 & 3.22 & 4 & 21 \\
Comprehension & 15.09 & 2.79 & 8 & 20 \\
Sophisticated & & & & 21 \\
$\quad$ Prior Knowledge & 12.19 & 3.44 & 1 & 9 \\
Comprehension & 16.07 & 2.51 & & \\
\hline
\end{tabular}




\section{Discussion and Conclusions}

To our knowledge, this is the first study that has attempted to identify conceptually related belief profiles and from which it is possible to postulate an impact on the approximation to comprehension across multiple texts.

With respect to the relationship between the two types of beliefs studied, in accordance with our hypothesis, and replicating prior findings (Mateos et al., 2011), our results support the claim of theoretical convergence of the two types of belief; epistemological beliefs were associated with reading beliefs. More specifically, on the one hand, students who held a simple knowledge belief or a certain knowledge belief, displayed less agreement with transactional reading beliefs. On the other hand, students who held a certain knowledge belief displayed greater agreement with transmission reading beliefs. Furthermore, the results of the cluster analysis support the multidimensional configuration of epistemological and reading beliefs, as in Buehl and Alexander (2005) and in Ferguson and Bråten (2013). In our study, both profiles identified are characterised by beliefs which cannot be considered really naïve in any of the cases, which, to a large extent, can be attributed to the tertiary level of education of our participants. As research in this field suggests, the higher the students' educational level, the more complex and sophisticated, and the more inter-related, the epistemological beliefs they hold tend to be (e.g. Schommer, 1998). However, we did identify two different profiles, one more naïve and the other more sophisticated, with the widest gap separating the two being between belief of certain knowledge and transactional reading belief.

These profiles are not independent of the area of study and gender, the domain of engineering and architecture being where the greatest differences occur between the sophisticated profile shown by a greater proportion of women, and the naïve profile, shown in a higher proportion by men. These results point in the same direction as those obtained in some researches carried out with secondary school students (Mason et al., 2006) and with undergraduates in the domain of engineering (King \& Magun-Jackson, 2009), in which women showed more sophisticated beliefs than men. Similar results for 
gender and domain have been found in another study carried out by Lordán and Solé (in preparation) with undergraduates in the field of reading beliefs.

Our work has shown a further interesting interaction that adds to previous findings. In particular, the profile for beliefs held by women was not associated with the area of knowledge in which they were conducting their studies. However, in the case of male participants, these were found to be related. Thus, men studying engineering and architecture showed a naïve belief profile. In contrast to this, men studying psychology tended to present a more sophisticated profile. Such interaction should be taken into account when interpreting the differences in beliefs among domains (Hakan \& Münire, 2012), according to the distribution of men and women in different academic disciplines and comparing the weight of gender and other associated variables (Peterson \& Parr, 2012).

The beliefs profile, in contrast, was not associated with the level of educational experience. This result follows the same line as other previous works that likewise did not identify differences between university students in different years (Hakan \& Munire, 2012; Jehng, Johnson, \& Alexander, 1993). As suggested in some studies, the tuition received throughout a university degree course does not necessarily produce an epistemic change; for this to occur, it appears that specific instruction pursuing this aim is necessary (Kienhues, Bromme, \& Stahl, 2008; Neely, 2014).

With respect to the role of epistemological and reading beliefs on the comprehension of multiple texts, our results expand those obtained in other studies, which have revealed the effect of each of them independently. After controlling prior knowledge, students with a more sophisticated profile of epistemological and reading beliefs obtained a higher level of multiple text comprehension than those students with a more naïve profile. Consistent with prior research (Bråten et al., 2011; Day \& Wang, 2007), this result can be attributed, to some extent, to the fact that students with more sophisticated beliefs get involved in a deeper comprehension of the different sources and this favours their ability to process information and make inferences - both at an intratextual level and at an inter-textual one. We believe that our results can also be interpreted in these terms, which enables us to better understand said relationship. Specifically, the multidimensional configuration of epistemological beliefs and reading beliefs 
indicates a moderate degree of relationship between both constructs of beliefs. In this respect, students who understand knowledge in a more sophisticated way tend to view reading less as a transmissive process and more transforming of knowledge and, therefore, they approach the task of text comprehension as a transactional process between the information presented in the multiple sources together with their personal prior knowledge and experience. This specific way of perceiving and approaching the task would facilitate a deeper processing of the information presented in the texts and also derive conclusions which require integration (within each text and across the various sources).

In spite of the importance of these findings, the size of the effect of the configuration of epistemological and reading beliefs on comprehension, although significant, is a small to moderate effect. However, it is very similar to that obtained by Ferguson and Bråten (2013) in the only study that examined how students profiles based on epistemic beliefs and knowledge differ with respect to multiple-text-comprehension $\left(\eta^{2}=.069\right)$ and is somewhat less than that obtained in other research which studied the separate effect of different epistemological beliefs. The small to moderate effect found here may be due to the convergence of several factors. On the one hand, in spite of having controlled the effect of prior knowledge on comprehension, it is worth underlining that the average level of knowledge about the subject presented to the participants in the study was not high (12.15 out of 20). As some authors (Boscolo \& Mason, 2003) have indicated, a high level of knowledge about a subject may contribute to making more appropriate and relevant elaborations and inferences that improve comprehension. In fact, when comparing the comprehension of multiple sources to tasks which require, whether explicitly or not, that the reader constructs arguments while reading from sources on a subject, only students with a high level of prior knowledge have a differential performance, carrying out deeper comprehensions under explicit instructions to read in order to debate (Gil, Bråten, Vidal-Abarca \& Strømsø, 2010). Taking into account the above, it could be argued that having a medium level of knowledge about a subject (as is the case in this study) could minimise the impact of beliefs on comprehension. On the other hand, the high degree of openness of the comprehension task presented to our students could also cushion the impact of beliefs on comprehension. Bråten and Strømsø (2010) analysed the role of epistemological beliefs maintained by students in different tasks 
which required the comprehension of multiple texts (argument, summary, and global understanding). Results showed that the effect of epistemological beliefs on comprehension from multiple texts only became apparent in the tasks of argumentation and summarising, and not under global understanding conditions (analogous to the condition used in our study). In accordance with Bråten and Strømsø (op.cit. p. 23), readers holding sophisticated epistemic beliefs in the global understanding condition processed contents more superficially and may have paid little attention to the source documents. When later presented with inference test sentences combining information from several of the source documents, the readers might have made it difficult for them to judge whether the test sentences represented valid or invalid inferences. Nevertheless, this tentative explanation must be examined further in future research.

Moreover, in some prior research (Bråten et al., 2011; Bueh \& Alexander, 2005), the role of topic-specific and domain-specific epistemological beliefs was investigated. It is possible that the minor effect of the beliefs in our case may be due to some extent to the fact that the beliefs investigated were general and not specific to the topic dealt with in the texts.

Finally, the somewhat low reliability of some of the measurements used, in particular the reading beliefs scales and the global comprehension across multiple texts score, may also have limited the effect in the findings. However, given that the measures were constructed and used for research purposes and not for making important and irreversible decisions concerning individuals, its relatively low reliability may still be considered within the acceptable range (Kerlinger \& Lee, 2000; Fishman \& Galguera, 2003). Taken as a whole, all the above factors may have contributed to mitigating the effect of beliefs on text comprehension found in this study.

In spite of these restrictions and transcending our specific goals, the results found support the already well-established (Buehl \& Alexander, 2005; Schommer, 1990) idea of inter-relation among independent beliefs. Beyond the relationship between different beliefs and the degree of comprehension obtained, our study enables us to identify students with coherent belief profiles and to show the impact of these profiles on comprehension tasks across multiple texts. From a conceptual point of view, our research, within its specificity, goes deeper towards a promising approximation which 
seeks to establish how certain belief systems of different levels relate to and have an impact on learning, for example both general and specific domains (Buehl \& Alexander, 2005; Bråten et al., 2011). In this respect, a conceptual problem which is posed is the consideration itself of reading beliefs, which are not general epistemological beliefs but neither are they specific to a domain (mathematics, science), at least not to the same extent. From the point of view of the research, knowing the existence of profiles which may influence the results of comprehension may contribute to understanding and interpreting the results reached in this area. From the point of view of the educational implications, the identification of students with similar profiles in relevant factors may help to understand their approximation to the comprehension across multiple texts, as well as thinking about interventions which take into account the inter-relation between both types of beliefs, and which favour those which are more beneficial towards learning. Our paper begs the consideration of the benefit of encouraging students to reflect on the complex and changing nature of the knowledge they are required to manage as well as the process of reading in which they are involved when faced with multiple sources. Beyond current determinants, a specific way of perceiving reading underlies said processes. Although insufficient, both conditions may contribute to the success of deeper learning experiences in line with the demands of higher levels of education.

\section{Acknowledgments}

This work was funded under the National Programme for Basic Research Projects 2014-2016 by the Spanish Ministry of Economy and Competitiveness (Grant EDU2013-46606-C2-1 \& 2-R).

\section{References}

Alexander, P. A., \& Jetton, T. L. (2000) Learning from text: a multidimensional and developmental perspective. In M. L. Kamil, P. B. Mosenthal, P. D. Pearson \& R. Barr (Eds.), Handbook of Reading Research (Vol. III, pp. 285-310). Mahwah, NJ: Erlbaum. 
Boscolo, P., \& Mason, L. (2003). Topic knowledge, test coherence, and interest: How they interact in learning from instructional texts. Journal of Experimental Education, 71, 126-148. DOI: 10.1080/00220970309602060.

Bråten, I., Britt, M.A., Strøms $\varnothing$, H.I., \& Rouet, J. F (2011). The role of epistemic beliefs in the comprehension of multiple expository texts: toward an integrated model. Educational Psychologist, 46, 48-70. DOI:10.1080/00461520.2011.538647.

Bråten, I., \& Strøms $\varnothing$ H.I. (2010). Effects of task instruction and personal epistemology on the understanding of multiple texts about climate change. Discourse Processes, 47, 1-31. DOI: 10.1080/01638530902959646.

Britt, M.A., Perfetti, C.A., Sandak, R., \& Rouet, J.F. (1999). Content integration and source separation in learning from multiple texts. In S.R. Goldman, A.C. Graesser, \& P.van den Broek (Eds.), Narrative, comprehension, causality and coherence: Essays in honor of Tom Trabasso (pp. 209-233). Mahwah, NJ: Erlbaum.

Buehl, M.M. (2008). Assessing the multidimensionality of students' epistemic beliefs across diverse cultures. In M.S. Khine (Wd.), Knowing, knowledge, and beliefs: Epistemological studies across diverse cultures (pp.65-112). New York: Springer.

Buehl, M. M., \& Alexander, P. A. (2005). Motivation and performance differences in students' domain-specific epistemological belief profiles. American Educational Research Journal, 42, 696-726. DOI: 10.3102/00028312042004697

Dai, D.Y. \& Wang, X. (2007). The role of need for cognition and reader beliefs in text comprehension and interest development. Contemporary Educational Psychology, 32, 332-347. DOI:10.1016/j.cedpsych.2006.05.002

Everitt, B.S., Landau, S., \& Leese, M. (2001). Cluster Analysis. London: Arnold.

Fishman, J.A. , \& Galguera, T. (2003). Introduction to test construction in the social and behavioral sciences. New York: Rowman and Littlefield Publishers.

Ferguson, L.E, \& Bråten, I. (2013). Students profiles of knowledge and epistemic beliefs: Changes and relations to multiple-text comprehension. Learning and Instruction, 25, 49-61. DOI:10.1016/j.learninstruc.2012.11.003.

Gil, L., Bråten, I., Vidal-Abarca, E., \& Strømsø, H.I. (2010). Summary versus argument tasks when working with multiple documents: Which is better for whom? ContemporaryEducationalPsychology 35, 157-173.

DOI: 10.1016/j.cedpsych.2009.11.002

-- 249 -- $\quad$ Electronic Journal of Research in Educational Psychology, 14(2), 226-252. ISSN:1696-2095. 2016 no. 39 http://dx.doi.org/10.14204/ejrep.39.15058 
Goldman, S. (1997). Learning from text. Reflection on the past and suggestion for the future. Discourse Processes, 23, 357-398. DOI: 10.1080/01638539709544997

Hakan, K. \& Münire, E. (2012). Profiling differences in undergraduates' epistemological beliefs: gender, domain and grade differences. Procedia - Social and Behavioral Sciences, 31, 738-744. DOI:10.1016/j.sbspro.2011.12.133

Hofer, B. K. \& Pintrich, P. R. (1997). The development of epistemological theories: beliefs about knowledge and knowing and their relation to learning. Review of Educational Research, 67, 88-140. DOI: 10.3102/00346543067001088

Hofer, B.K., \& Pintrich, P.R. (Eds.). (2002). Personal epistemology. The psychology of beliefs about knowledge and knowing. Mahwah, NJ: Erlbaum.

Jehng, J. J., Johnson, S. D. \& Anderson, R. C. (1993). Schooling and students' epistemological beliefs about learning. Contemporary Educational Psychology, 18, 23-35. DOI: 10.1006/ceps.1993.1004

Kardash, C. M., \& Scholes, R. J. (1996). Effects of pre-existing beliefs, epistemological beliefs, and need for cognition on interpretation of controversial issues. Journal of Educational Psychology, 88, 260-271. DOI:10.1037/0022-0663.88.2.260

Kerlinger, F.N., \& Lee, H.B. (2000). Foundations of behavioral research ( $4^{\text {th }}$ edition). Forth Worth, TX: Harcourt College Publishers.

King, B. A., \& Magun-Jackson, S. (2009). Epistemological beliefs of engineering students. The Journal of Technology Studies, 35, 56-64. DOI: 10.21061/jots.v35i2.a.6

Kienhues, D., Bromme, R., \& Stahl, E. (2008). Changing epistemological beliefs: The unexpected impact of a short-term intervention. British Journal of Educational Psychology, 78, 811-816. DOI: 10.1348/000709907X268589.

Lordán, E., \& Solé, I. (in preparation). Differences on Undergraduate Students' Reading Beliefs between Knowledge Domains, Academic Years and Genders.

Mason, N., Boldrin, A., \& Zurlo, G. (2006). Epistemological understanding in different judgment domains: Relationship with gender, gender level and curriculum. International Journal Educational Research, 45, 43-56. DOI:10.1016/j.ijer.2006.08.003

Mateos, M., Cuevas, I., Martín, E., Martín, A., Echeita, G., \& Luna, M. (2011). Reading to write an argumentation: the role of epistemological, reading and writing be- 
liefs. Journal of Research in Reading, 34, 281-297. DOI: 10.1111/j.14679817.2010.01437.x

Mateos, M., \& Solé, I. (2009). Synthesising information from various texts: A study of procedures and products at different educational levels. European Journal of Psychology of Education, 24, 435-451. DOI: 10.1007/BF03178760

Mateos, M., Villalón, R., De Dios, M. J., \& Martín, E. (2007). Reading-and-writing tasks on different university degree courses: What do the students say they do? Studies in Higher Education, 32, 489-510. DOI:10.1080/03075070701476183

Muis, K.R., Bendixen, L.D., \& Haerle, F. C. (2006) Domain-generality and domainspecificity in personal epistemology research: Philosophical and empirical reflections in the development of a theoretical framework. Educational Psychology Review, 18, 3-54. DOI 10.1007/s10648-006-9003-6

Nayebi, R. \& Tahiri, A. (2013). A study of epistemological beliefs of EFL learners across gender and educational level. International Journal of Research Studies in Psychology, 3, 17-28. DOI: 10.5861/ijrsp.2014.754

Neely, M.E. (2014). Epistemological and writing beliefs in a first-year college writing course: Exploring shifts across a semester and relationships with argument quality. Journal of Writing Research, 6, 141-170.DOI:10.17339/jowr-2014.06.02.3

Ordoñez, X.G., Ponsoda, V., Abad, F.J., \& Romero, S. J. (2009). Measurement of epistemological beliefs: Psychometric properties of the EQEBI test scores. Educational and Pshychological Measurement, 69, 287-302. DOI: 10.14718/ACP.2016.19.1.4

Peterson, S. S., \& Parr, J. M. (2012). Gender and literacy issues and research: Placing the spotlight on writing. Journal of Writing Research, 3, 151-161. DOI:10.17239/jowr-2012.03.03.1

Pieschl, S., Stahl, E., \& Bromme R. (2013). Adaptation to context as core component of self-regulated learning. The example of complexity and epistemic beliefs. In R. Azevedo \& V. Aleven (Eds.), International handbook of metacognition and learning technologies (pp. 53-65). New York: Springer.

Schommer, M. (1990). Effects of beliefs about the nature of knowledge on comprehension. Journal of Educational Psychology, 82, 498-504. DOI:10.1037/00220663.82.3.498 
Schommer, M. (1993).Epistemological development and academic performance among secondary strudents. Journal of Educational Psychology, 85, 406-411. DOI:10.1037/0022-0663.85.3.406

Schommer, M. (1998). The influence of age and education on epistemological beliefs. British Journal of Educational Psychology, 68, 551-562. DOI: 10.1111/j.20448279.1998.tb01311.x

Schommer-Aikins, M. (2002). An evolving theoretical framework for an epistemological belief system. In B. K. Hofer \& P. R. Pintrich (Eds.), Personal epistemology: The psychology of beliefs about knowledge and knowing (pp.103-118). Mahwah, NJ: Erlbaum.

Schraw, G. (2000). Reader beliefs and meaning construction in narrative text. Journal of Educational Psychology, 92, 96-106. DOI:10.1037/0022-0663.92.1.96

Schraw, G., Bendixen, L.D., \& Dunkle, M.E. (2002). Development and validation of the Epistemic Belief Inventory (EBI). In B.K. Hofer \& P.R. Pintrich (Eds.), Personal epistemology: The psychology of beliefs about knowledge and knowing (pp.261-275). Mahwah, NJ: Erlbaum.

Schraw, G., \& Bruning, R. (1996). Readers' implicit models of reading. Reading Research Quarterly, 31, 290-305. DOI: 10.1598/RRQ.31.3.4

Simpson, M. L. \& Nist, S. L. (2000) An update on strategic learning: it's more than textbook reading strategies. Journal of Adolescent \& Adult Literacy, 43, 528541. Retrieved from http://www.jstor.org/stable/40016831

Solé, I., Mateos, M., Miras, M., Martín, E., Castells, N., Cuevas, I., \& Grácia, M. (2005). Lectura, escritura y adquisición de conocimientos en educación secundaria y educación universitaria. Infancia y Aprendizaje, 28, 329-347. DOI: $10.1174 / 0210370054740241$

Tynjälä, P. (2001). Writing, learning and the development of expertise in Higher Education. In P. Tynjälä, L. Mason, \& K. Lonka (Eds.), Writing as a learning tool. Integrating theory and practice (pp. 37-56). Dordrecht, The Netherlands: Kluwer Academic Press. 